\title{
Metabolic Syndrome in People with HIV/AIDS
}

\author{
Ana Paula Werberich ${ }^{1}$, Juliana Ceren ${ }^{1}$, Jayder Lucas Hotts Romancini ${ }^{2}$, \\ Giuliano Gomes de Assis Pimentel ${ }^{1}$, Miguel Spack Junior ${ }^{1}$, Áurea Regina Telles Pupulin ${ }^{3}$ \\ ${ }^{1}$ Department of Medicine, Universidade Estadual de Maringá, Maringá, Brazil; ${ }^{2}$ Department of Physical Education, Universidade \\ Estadual de Maringá, Maringá, Brazil; ${ }^{3}$ Department of Basic Health Sciences, Universidade Estadual de Maringá, Maringá, Brazil. \\ Email: artpupulin@uem.br
}

Received July $16^{\text {th }}, 2013$; revised August $12^{\text {th }}, 2013$; accepted August $19^{\text {th }}, 2013$

Copyright (c) 2013 Ana Paula Werberich et al. This is an open access article distributed under the Creative Commons Attribution License, which permits unrestricted use, distribution, and reproduction in any medium, provided the original work is properly cited.

\begin{abstract}
Background: Highly Active Antiretroviral Therapy (HAART) has changed the clinical picture of HIV infection by reducing morbidity and mortality rates in the population. However, alterations in lipid metabolism leading to hypertriglyceridemia, hypercholesterolemia, insulin resistance, hyperglycemia and redistribution of body fat, which are risk factors for cardiovascular diseases, have emerged. Metabolic Syndrome (MS) is a complex disorder represented by a set of cardiovascular risk factors commonly associated with central adiposity and insulin resistance. Aim: Current paper evaluates the prevalence of MS in patients with HIV/AIDS using HAART from a reference Center in southern Brazil. Methods: Samples comprised patients who had the infection for at least five years and were undergoing antiretroviral therapy. Metabolic syndrome was identified according to the National Cholesterol Education Program Expert Panel on Detection, Evaluation, and Treatment of High Blood Cholesterol in Adults (NCEP-ATPIII). A physical examination was performed by evaluating percentage of body fat by bio-impedance and measuring blood pressure, determination of Body Mass Index and Waist-Hip Ratio, glycaemia, total cholesterol, HDL cholesterol, LDL cholesterol and triglycerides. Results: 184 patients were evaluated. MS prevalence was 30\% (55 patients), with 30 (16.3\%) males and 25 (13.7\%) females. Conclusions: Brazil was among the first country profoundly impacted by the HIV/AIDS epidemic but today, Brazil has less than $1 \%$ adult HIV prevalence, implemented treatment and prevention programs early in the epidemic. Whereas there is currently a significant increase in the survival of HIV patients by HAART, the patients reveal a higher prevalence of Metabolic Syndrome in this specific population requiring political strategy of care to this population.
\end{abstract}

Keywords: HIV/AIDS; Metabolic Syndrome; Metabolic Abnormalities; Brazil

\section{Introduction}

Brazil has currently 656,701 registered AIDS cases, with 38,776 new registered cases of HIV infection in 2012. The above data rank second for reported cases for AIDS in the Americas [1].

The Brazilian government's policy to respond to AIDS with the universal, free supply of antiretroviral drugs and medications for opportunistic diseases through the public health system was heavily questioned, especially when the policy was first implemented in the 1990s. The program's success is now acknowledged internationally, due not only to this key component, but also to interaction with other government ministries, in constant dialogue with social movements and the scientific community. Universal access to antiretroviral therapy has led to a significant reduction in morbidity and mortality [2]. However, they have also widened changes in lipid metabolism leading to hypertriglyceridemia, hypercholesterolemia and other metabolic disorders, such as insulin resistance, hyperglycemia and redistribution of body fat which are risk factors in cardiovascular diseases [3]. These changes are known as the lipodystrophy syndrome (HIVLS), officially described by the Food and Drug Administration (FDA) in 1997, and also known as the syndrome of the redistribution of body fat, or Metabolic Syndrome, associated with antiretroviral therapy or, more recently, dyslipidemic lipodystrophy associated with HIV/HAART [4-6].

Metabolic syndrome (MS) is a complex disorder represented by a set of cardiovascular risk factors commonly associated with central adiposity and insulin resistance. 
The importance of the epidemiological aspect, responsible for increased mortality cardiovascular estimated at 2.5 times, should be highlighted. Although MS still lacks a well-established definition, there is a consensus indicating that increased blood pressure, glucose metabolism and lipid disorders and overweight are permanently associated with increased cardiovascular morbidity and mortality. The above has been observed in both developed and developing countries. According to NCEP-ATP III, MS represents the combination of at least three of the following components, namely, abdominal obesity, triglycerides $>150 \mathrm{mg} / \mathrm{dL}$, low levels of HDL-cholesterol, blood pressure $>130 \mathrm{mmHg}$, and fasting glucose $>110$ $\mathrm{mg} / \mathrm{dL}$ [7].

Few studies have been conducted in Brazil on MS in patients with AIDS using HAART [8-11].

Current study evaluates the prevalence of metabolic syndrome in HIV infected patients, from a two public health Center for AIDS Care and Treatment in Parana, southern Brazil.

\section{Methodology}

\subsection{Study Setting and Design}

One hundred and eighty-four patients with HIV/AIDS were evaluated. The population under analysis consisted of HIV/AIDS patients attended to at the $15^{\text {th }}$ Regional Health Unit in Maringa and at the $17^{\text {th }}$ Regional Health Unit in Londrina PR Brazil, covering 50 counties in the north and northwestern region of the state of Paraná, Brazil. The sample consisted of patients with at least a five-year infection using antiretroviral therapy (HAART). Patients were selected for the study after receiving the required explanations on STD/AIDS at the nuclei of Maringa and Londrina, and signed the consent form approved by the Committee for Ethics in Research involving Humans of the State University of Maringa. Survey comprised a prevalence study with a convenience sample, calculated by EpiInfo 5.5.1-2008 at a 90\% confidence level.

\subsection{Participant Recruitment and Data Collection}

Socioeconomic data were collected by a closed questionnaire comprising age, duration of infection, family income, education, alcohol/illegal drugs, use of antiretroviral drugs, rate of CD4 + T cells and the occurrence of opportunistic infections. The interviews were individual, previously scheduled, with an average duration of twenty minutes.

Patients' physical examination was subsequently performed to determine fat percentage using a fat control bio-impedance monitor Omron HBF 306 INT, and to determine weight and height for Body Mass Index (BMI = weight/height ${ }^{2}$ ). Height was measured by stadiometer coupled to Welmy 200 with balance scale to the nearest $0.5 \mathrm{~cm}$, with attached cursor for easy reading. Height determination was performed by placing the patient barefoot on the base of the stadiometer, in an upright posture, with feet together, arms pending down the body, touching the posterior surface of the body in scale measurements.

Body weight was measured with leverage Welmy balance at $100 \mathrm{~g}$ precision. The patient was barefoot and with as little clothing as possible. Patients were requested to position themselves at the center of the scale platform and remained upright, with arms down the body and staring ahead so that no oscillations occurred at the time of registration. The balance was checked before and after weighing every ten patients.

The waist was measured in cm with an inelastic tape, at midpoint between the iliac crest and the outer face of the last rib. The hip was measured in centimeters with inelastic tape at the iliac spine. Waist-hip ratio (WHR) was obtained by the ratio between waist and hip circumferences.

Standardized assessments of blood pressure were conducted using a validated automatic device (OMRON CP705), and the average of eight measurements in two office visits was used to diagnose hypertension.

So that metabolic parameters could be evaluated, blood samples were collected after a 12-hour fast. Dosages were performed for fasting glycaemia, triglycerides, total cholesterol, HDL-cholesterol and LDL-cholesterol. All biochemical measurements were performed with specific commercial kits using enzymatic colorimetric method according to the manufacturer's specifications.

\subsection{Data Analysis}

Data entry analysis was done by Graph Pad Prism program 5.00 for frequency analysis, followed by chi-square test at $\mathrm{p}<0.05$ significance level.

\section{Results}

\subsection{Demographic Characteristics of Population}

One hundred and eighty-four patients were evaluated. Gender distribution comprised 51.5\% males and 48.5\% females. Females' age ranged between 26 and 64 years (mean 42 years) and males' age ranged between 20 and 56 (mean 40 years).

Further, 73.8\% received primary education, 23\% secondary education and 3\% never attended school. Lowest schooling occurred in females. Whereas $74 \%$ of females had only attended elementary school, lack of schooling in males reached $34 \%$.

All patients were using HAART for at least five years. 


\subsection{Frequency of Metabolic Abnormalities of Population}

Biochemical changes in blood glucose occurred in 43 patients (23\%), or rather, 16 (8\%) females and 27 (15\%) males.

Table 1 shows abnormalities in lipid levels. Abnormal HDL cholesterol occurred in 114 (61.9\%) patients, featuring high risk rates, with no difference between males and females. Regarding levels of blood triglycerides, 57 (30.9\%) patients had high levels with no difference between male and female percentage.

Abdominal obesity was reported in 42 (23\%) patients, with no significant difference between males and females. Table 2 shows the results of classification according to Heyward \& Stolarczyk [12].

Blood pressure was high in 23 (12.5\%) patients, or rather, 14 (7.6\%) males and 9 (5\%) females.

Table 3 shows fat percentage according to classification by Pollock \& Wilmore [13] with regard to CD4+ level, $71.4 \%$ registered rates above 200 cells $/ \mathrm{mm}^{3}$, where as $28.6 \%$ of patients had rates equal to or below the above rate.

Table 4 shows the prevalence of metabolic syndrome in 55 (30\%) patients, or rather, 30 (16.3\%) males and 25 (13.7\%) females. Metabolic Syndrome represents the combination of least three components listed.

\section{Discussion}

Current research reinforces the occurrence, evidenced by several authors, of HAART impact on the metabolism of lipids and glucose. Dyslipidemia associated with HAART was characterized by elevated levels of LDL-cholesterol and by low levels of HDL cholesterol. The above alterations have been associated with the development of atherosclerosis and its complications, such as myocardial infarction and peripheral vascular disease [14,15].

Current results corroborate studies on the undisputed importance of HAART with its high patient survival, but also on the concomitant emergence of the SLHIV-associated Metabolic Syndrome and its cardiovascular metabolic risks [3]. Another metabolic alteration has been reported in HIV lipodystrophy syndrome (SLD), known as fat redistribution syndrome, which causes an accumulation of fat in the dorso-cervical (buffalo hump) and abdominal region. Fat redistribution with abdominal lipohypertrophy predisposes the patient to cardiovascular disease risk due to visceral fat, directly associated with a higher incidence of changes in serum lipids and insulin resistance, with a rise in risks for the development of Type 2 diabetes [16]. This study is well established as shown in Table 2, classification of cardiovascular risk in these patients have a higher prevalence of medium and high risk. Most patients had fat percentage of average to poor (Table 3).

Kramer et al. [17] reported that HIV dyslipidemia in the HAART therapy patient is characterized by high LDL-cholesterol and reduced level of HDL-cholesterol. The authors also suggested that the factors that led patients to have HIV dyslipidemia are still not clearly elucidated. No one knows for sure whether it is directly caused by HAART or whether it is the product of several factors such as antiretroviral therapy, genetic predisposition, diet and exercise, or such factors as host response to HIV infection.

Farhi et al. [18] conducted a study at a university hospital in Rio de Janeiro, Brazil, with 268 HIV patients and concluded that in male patients the prevalence of dyslipidemia was higher when compared to that of females, and that family history of dyslipidemia was directly related to the occurrence of dyslipidemia and the time of the use of HAART by patients.

Research by Smith et al. [19] in São Paulo, Brazil, with 319 patients divided into HIV HAART users and non-users showed that the concentrations of total cholesterol, triglycerides and glucose were significantly higher among patients taking HAART. These data imply a high prevalence of metabolic abnormalities, particularly high levels of cholesterol and triglycerides, in patients treated with HAART drug therapy.

Almeida [20] observed significant increases in total cholesterol, triglycerides and glucose in 110 patients after treatment with HAART. Glucose levels increased as a result of HAART in this study even though gender, smoking, intravenous drug use and age did not cause significance levels of total cholesterol, triglyceride and glucose levels during treatment.

Although the main focus of metabolic changes in HIV patients is attributed to the side effects of HAART, studies from the pre-HAART condition established that HIV

Table 1. Prevalence of hyperglycemia, hypercholesterolemia and hypertriglyceridemia in HIV patients using HAART. $\mathbf{n}=$ 184.

\begin{tabular}{cccccc}
\hline $\begin{array}{c}\text { Patients HIV } \\
\mathbf{n}=\mathbf{1 8 4}\end{array}$ & Glucose $>100 \mathrm{mg} / \mathrm{dL}$ & $\mathrm{CT}>200 \mathrm{mg} / \mathrm{dL}$ & $\begin{array}{c}\mathrm{HDL}<50 \mathrm{mg} / \mathrm{dL} \\
\text { or }<40 \mathrm{mg} / \mathrm{dL}\end{array}$ & $\mathrm{LDL}>160 \mathrm{mg} / \mathrm{dL}$ & $\mathrm{TG}>150 \mathrm{mg} / \mathrm{dL}$ \\
\hline $\mathbf{n}$ & 43 & 47 & 114 & 82 & 57 \\
$\%$ & $23 \%$ & $26 \%$ & $61.9 \%$ & $45 \%$ & $30.9 \%$ \\
\hline
\end{tabular}

CT $=$ Cholesterol Total, HDL $=$ Cholesterol HDL, $\mathrm{LDL}=$ Cholesterol LDL, $\mathrm{TG}=$ Triglycerides. 
Table 2. Cardiovascular risk classification according to the relationship between waist and hips of HIV/AIDS patients. $\mathbf{n}=\mathbf{1 8 4}$.

\begin{tabular}{ccc}
\hline Risk Classification & $\mathbf{n}$ & $\mathbf{\%}$ \\
\hline Low & 32 & 17.4 \\
Moderate & 64 & 34.8 \\
High & 56 & 30.4 \\
Towering & 32 & 17.4 \\
\hline
\end{tabular}

Classification of Heyward \& Stolarczyk, 1996.

Table 3. Classification of fat percentage in HIV/AIDS patients. $\mathbf{n}=184$.

\begin{tabular}{ccc}
\hline Fat Percentage & $\mathbf{n}$ & $\mathbf{\%}$ \\
\hline Excellent & 44 & 23.9 \\
Well & 13 & 7.1 \\
Above media & 44 & 23.9 \\
Media & 35 & 19 \\
Bellow media & 4 & 2.3 \\
Bad & 35 & 19.2 \\
Very bad & 9 & 4.6 \\
\hline
\end{tabular}

Classification according to Pollock \& Wilmore, 1993.

Table 4. Prevalence of metabolic syndrome in HIV/AIDS patients. $\mathbf{n}=184$.

\begin{tabular}{ccc}
\hline Metabolic Syndrome Parameters & n & \% \\
\hline Abdominal obesity & 52 & 28 \\
Triglycerides $>150 \mathrm{mg} / \mathrm{dL}$ & 57 & 30.9 \\
HDL-cholesterol & 114 & 61.9 \\
$<50 \mathrm{mg} / \mathrm{dL}$ or $<40 \mathrm{mg} / \mathrm{dL}$ & 23 & 12.5 \\
Blood pressure $>130 \mathrm{mmHg}$ & 43 & 23 \\
Glycaemia $>100 \mathrm{mg} / \mathrm{dL}$ & 55 & 30 \\
\hline Metabolic syndrome &
\end{tabular}

infection itself would determine a more unfavorable lipid profile with hypertriglyceridemia and low HDL-cholesterol. Constan et al. [21] included a prognostic implication of these changes, or rather, the lower the count of $\mathrm{CD} 4+$, the greater are triglycerides levels and the lower are HDL-cholesterol levels. The patho-physiology of this association is not clear. There is still no consensus on the manner antiretroviral therapy enhances this lipid disorder and affects others associated with it, such as insulin resistance, diabetes mellitus, central obesity and lipodystrophy. Our study showed that even with levels of CD4+ above 200 cells $/ \mathrm{mm}^{3}$ found in a high alteration in levels of triglycerides and HDL-cholesterol.

Current study shows that changes in blood levels of HDL-cholesterol were high and corroborated the findings of the above authors to explain these changes as a result of the interaction HIV infection and antiretroviral therapy.

Hsue et al. [22] retrospectively evaluated the risk factors and clinical outcome of $68 \mathrm{HIV}$ patients hospitalized between 1993 and 2003 for unstable angina or myocardial infarction and compared the characteristics of this population to a control group of 68 seronegative individuals with a diagnosis of acute coronary artery condition. The prevalence of smoking and low HDL-cholesterol was higher among HIV-positive patients, while in the control group the prevalence for diabetes and dyslipidemia was higher. Although the rate of re-stenosis with clinical manifestations was higher in patients with AIDS and 29 angioplasties were performed in HIV-positive patients, only 11 were performed in the control group. It may be likewise inferred that low HDL-cholesterol may be a significant cardiovascular risk factor in HIV patients.

Brazil and South Africa were among the first countries profoundly impacted by the HIV/AIDS epidemic and had similar rates of HIV infection in the early 1990s. Today, Brazil has less than $1 \%$ adult HIV prevalence, implemented treatment and prevention programs early in the epidemic, and now has exemplary HIV/AIDS programs. South Arica, by contrast, has HIV prevalence of $18 \%$ and was, until recently, infamous for its delayed and inappropriate response to the HIV/AIDS epidemic. Although Brazil has achieved so sui generis these indices mainly due to free distribution of HAART may not be getting adequately monitor these patients. Thirty years since the first AIDS cases in Brazil few article related to appropriate monitoring by health services and early identification of patients with metabolic abnormalities inferring vulnerability increased.

\section{Conclusion}

In conclusion, the increasing number of antiretroviral agents, longer duration of HAART use, and aging of the HIV population, might contribute to the growing prevalence of metabolic syndrome and reduce the life expectancy of HIV-infected patients requiring political strategy of care to this population in Brazil.

\section{REFERENCES}

[1] Ministério da Saúde, "Manual de Assistência em HIV/ AIDS,” Programa Nacional de DST e AIDS, 2012. http://www.aids.gov.br/

[2] C. L. Szwarcwald and E. A. Castilho, "The HIV/AIDS Epidemic in Brazil: Three Decades,” Cad Saude Publica, 
Vol. 27, No. 1, 2011, pp. 4, 5.

[3] C. Jericó, “Metabolic Syndrome among HIV-Infected Patients: Prevalence, Characteristics, and Related Factors,” Diabetes Care, Vol. 28, No 1, 2005, pp. 132-137. http://dx.doi.org/10.2337/diacare.28.1.132

[4] A. M. M. Valente, “Alterações Metabólicas da Síndrome Lipodistrófica do HIV," Arquivos Brasileiros de Endocrinologia \& Metabologia, Vol. 49, No. 6, 2005, pp. 871881.

http://dx.doi.org/10.1590/S0004-27302005000600004

[5] D. P. Kotler, "HIV and Antiretroviral Therapy: Lipid Abnormalities and Associated Cardiovascular Risk in HIVInfected Patients," Journal of Acquired Immune Deficiency Syndromes, Vol. 49, Sppl. 2, 2008, pp. 79-85.

[6] D. J. Jevtovic, “The Metabolic Syndrome, an Epidemic among HIV-Infected Patients on HAART,” Biomedicine \& Pharmacotherapy, Vol. 63, No. 5, 2008, pp. 337-342. http://dx.doi.org/10.1016/j.biopha.2008.09.011

[7] NCEP-III-Expert Panel on Detection, Evaluation and Treatment of High Blood Cholesterol in Adults, "Executive Summary of the Third Report of the National Cholesterol Education Program (NCEP) Expert Panel on Detection, Evaluation and Treatment of High Cholesterol," JAMA, Vol. 285, No. 19, 2001, pp. 2486-2497. http://dx.doi.org/10.1001/jama.285.19.2486

[8] E. F. Silva, K. C. Bassichetto and D. C. Lewi, "Lipid Profile, Cardiovascular Risk Factors and Metabolic Syndrome in a Group of AIDS Patients," Arquivos Brasileiros de Cardiologia, Vol. 93, No. 2, 2009, pp. 113-118.

[9] L. G. Lauda, A. B. Mariath and L. P. Grillo, "Metabolic Syndrome and Its Components in HIV-Infected Individuals,” Revista da Associação Médica Brasileira, Vol. 57, No. 2, 2011, pp. 182-186. http://dx.doi.org/10.1590/S0104-42302011000200016

[10] P. R. Alencastro, S. C. Fuchs, F. H. Wolff, R. R. Oliveira, M. L. Ikeda, N. T. Barcellos and A. B. Brandao, "Independent Predictors of Metabolic Syndrome in HIV-Infected Patients," AIDS Patient Care STDS, Vol. 25, No. 11, 2011, pp. 627-634. http://dx.doi.org/10.1089/apc.2010.0360

[11] P. R. Alencastro, F. H. Wolff, R. R. Oliveira, M. L. Ikeda, N. T. Barcellos, A. B. Brandao and S. C. Fuchs, "Metabolic Syndrome and Population Attributable Risk among HIV/AIDS Patients: Comparison between NCEP-ATP III, IDF and AHA/NHLBI Definitions," AIDS Research and Therapy, Vol. 9, No. 1, 2012, p. 29. http://dx.doi.org/10.1186/1742-6405-9-29

[12] V. H. Heyward and L. M. Stolarczyk, "Body Composition and Children,” In: Applied Body Composition Assessment, Human Kinetics, Champaign, 1996, pp. 90-98.

[13] M. L. Pollock and J. H. Wilmore, "Exercícios na Saúde e na Doença; Avaliação e Prescrição para Prevenção e Reabilitação,” 2 Edition, Rio de Janeiro, Medsi, 1993.

[14] A. G. Bostom, L. A. Cupples, J. L. Jenner, J. M. Ordovas, L. J. Seman and P. W. Wilson, "Elevated Plasma Lipoprotein and Coronary Heart Disease in Men Aged 55 Years and Younger: A Prospective Study,” JAMA, Vol. 276, No. 7, 1996, pp. 544-548. http://dx.doi.org/10.1001/jama.1996.03540070040028

[15] M. L. F. Werner, “Alterações Metabólicas e de Distribuição da Gordura Corporal em Crianças e Adolescentes Infectados Pelo HIV/AIDS em uso de Drogas Antiretrovirais de Alta Potência,” Master's Dissertation in Child and Woman Health-Instituto Fernando Figueira (FIOCRUZ), Rio de Janeiro, 2005.

[16] A. S. Kramer, “Alterações Metabólicas, Terapia Antiretroviral e Doenças Cardiovasculares em Idosos Portadores de HIV," Arquivos Brasileiros de Cardiologia, Vol. 93, No. 5, 2009, pp. 561-568. http://dx.doi.org/10.1590/S0066-782X2009001100019

[17] L. Farhi, "Dislipidemia em Pacientes HIV/AIDS em uso de Anti-Retrovirais num Hospital Universitário, Rio de Janeiro, Brasil,” Jornal Brasileiro de Patologia Medico Laboratorial, Vol. 44, No. 3, 2008, pp. 175-184. http://dx.doi.org/10.1590/S1676-24442008000300004

[18] E. F. R. Silva, K. C. Bassichetto and D. S. Lewi, "Perfil Lipídico, Fatores de Risco Cardiovascular e Síndrome Metabólica em um Grupo de Pacientes com AIDS,” Arquivos Brasileiros de Cardiologia, Vol. 93, No. 2, 2009, pp. 113-118. http://dx.doi.org/10.1590/S0066-782X2009000800008

[19] S. E. M. Almeida, "Metabolic Changes Associated with Antiretroviral Therapy in HIV-Positive Patients," Revista de Saúde Pública, Vol. 43, No. 2, 2009, pp. 283-290. http://dx.doi.org/10.1590/S0034-89102009005000005

[20] J. Constans, J. L. Pelegrin and E. Pauchant, "Plasma Lipids in HIV Infected Patients; A Perspective Study in 95 Patients," European Journal of Clinical Investigation, Vol. 24, No. 6, 1994, pp. 416-420. http://dx.doi.org/10.1111/j.1365-2362.1994.tb02185.x

[21] P. Hsue, K. Girl and S. Erickson, "Clinical Features of Acute Coronary Syndrome in Patients with Human Immunodeficiency Virus Infection,” Circulation, Vol. 109, No. 3, 2004, pp. 316-319. http://dx.doi.org/10.1161/01.CIR.0000114520.38748.AA

[22] M. A. Noor, J. C. Lo, K. Mulligan, J. M. Schwarz, R. A. Halvorsen and M. Schambelan, "Metabolic Effects of Indinavir in Healthy HIV Seronegative Men,” AIDS, Vol. 15, No. 7, 2001, pp. 11-18. http://dx.doi.org/10.1097/00002030-200105040-00001 